\section{AB1041 PREVALENCE OF JUVENILE IDIOPATHIC ARTHRITIS (JIA) SUBGROUPS AND JIA-ASSOCIATED UVEITIS AMONG JIA PATIENTS ADMITTED TO REFERRAL PEDIATRIC RHEUMATOLOGY CLINICS IN TURKEY: A RETROSPECTIVE STUDY, JUPITER}

Sezgin Sahin ${ }^{1}$, Ceyhun Acarı ${ }^{2}$, Hafize Emine Sonmez ${ }^{3}$, Fatma Zehra Kilic ${ }^{4}$, Erdal Sag ${ }^{3}$, Hatice Adiguzel Dundar ${ }^{2}$, Amra Adrovic ${ }^{1}$, Selcan Demir ${ }^{3}$, Kenan Barut ${ }^{1}$, Yelda Bilginer ${ }^{3}$, Betül Sözeri' ${ }^{4}$, Erbil Unsal' ${ }^{2}$, Seza Özen ${ }^{3}$, Ozgur Kasapcopur'. ${ }^{1}$ Istanbul University Cerrahpasa, Cerrahpasa School of Medicine, Department of Pediatric Rheumatology, Istanbul, Turkey; ${ }^{2}$ Dokuz Eylul University, School of Medicine, Department of Pediatric Rheumatology, Izmir, Turkey; ${ }^{3}$ Hacettepe University, School of Medicine, Department of Pediatric Rheumatology, Ankara, Turkey, ${ }^{4}$ Umraniye Training and Research Hospital, Department of Pediatric Rheumatology, Istanbul, Turkey

Background: Juvenile Idiopathic Arthritis (JIA) is a chronic childhood arthritis with onset before age of 16 and has a significant degree of morbidity that negatively affects quality of life. Uveitis, which is defined as the inflammation of the iris, ciliary body and choroid, is the most common cause of morbidity of JIA. This study was planned to collect data from a Turkish cohort to provide the initial national prevalence data of patients with JIA.

Objectives: The objective of this study was to determine the frequency of JIA subtypes in Turkey. We also aimed to assess the frequency and characteristics of eye involvement in JIA.

Methods: This national, non-interventional, multicenter, observational study was conducted in a retrospective manner in four study centers which were main referral pediatric rheumatology clinics across Turkey. Data on patient demography, medical history, JIA disease characteristics, laboratory data, cases of JIA-associated uveitis, JIA treatment history and data on other comorbidities were collected from a cohort of 500 patients.

Results: Oligoarthritis $(n=194,38.8 \%)$ was the most common JIA disease characteristic in this study cohort. The frequency of the subgroups was as follows: Enthesitis-Related Arthritis (ERA) in $23.2 \%(n=116)$, polyarthritis in $15.6 \%(n=78)$, systemic arthritis in $12.2 \%(n=61)$, psoriatic arthritis in $5.2 \%(n=26)$, idiopathic arthritis in $2.8 \%(n=14)$ and polyarthritis $(R F+)$ in $2.2 \%(n=11)$ of patients were identified. The most frequently prescribed treatment for JIA was methotrexate $(n=384,76.8 \%)$. A total of 85 comorbidities were reported, and the most frequently reported comorbidity was Familial Mediterranean Fever (FMF) ( $n=63,12.6 \%)$.

The number of patients with $\mathrm{JIA}$-associated uveitis diagnosis was 34 $(6.8 \%)$, and the mean duration of uveitis was $3.2( \pm 2.3)$ years. The mean duration between the initial JIA diagnosis and diagnosis of uveitis was $1.8( \pm 1.9)$ years. Among 34 patients with uveitis, 45 eye involvements were identified; left eye, right eye and both eyes were affected in 5,8 and 16 patients, respectively. Five patients (14.7\%) had uveitisrelated complications that required surgical intervention.

Conclusion: The main difference from the European Caucasian population is the lower frequency of oligoarticular JIA and higher frequency of ERA in Turkish JIA patients. Uveitis was also somewhat lower than expected. Geographic and ethnic factors, that may affect these differences, need further investigation.

\section{REFERENCES}

[1] Barut K, Adrovic A, Şahin S and Kasapçopur Ö. Juvenile Idiopathic Arthritis. Balkan Med J. 2017;34:90-101.

[2] Demirkaya E, Ozen S, Bilginer $Y$, et al. The distribution of juvenile idiopathic arthritis in the eastern Mediterranean: results from the registry of the Turkish Paediatric Rheumatology Association. Clin Exp Rheumatol. 2011;29:111-6

Acknowledgement: This JUPITER study is a collaborative study.

Disclosure of Interests: Sezgin Sahin: None declared, Ceyhun Acarl: None declared, Hafize Emine Sonmez: None declared, Fatma Zehra Kilic: None declared, Erdal Sag: None declared, Hatice Adiguzel Dundar: None declared, Amra Adrovic: None declared, Selcan Demir: None declared, Kenan Barut: None declared, Yelda Bilginer: None declared, Betül Sözeri: None declared, Erbil Unsal Grant/research support from: Novartis, AbbVie, Roche, Koçak Pharma, Speakers bureau: Novartis, AbbVie, Roche, Koçak Pharma, Seza Özen Consultant for: Seza Ozen is receiving consultancy fees from Novartis, Speakers bureau: Roche, Ozgur Kasapcopur: None declared

DOI: 10.1136/annrheumdis-2019-eular.3138

\section{$\mathrm{AB} 1042$ \\ THE EFFECT OF INTRA-ARTICULAR STEROID INJECTION ON THE CARTILAGE THICKNESS IN JUVENILE IDIOPATHIC ARTHRITIS}

Nihal Sahin, Sumeyra Ozdemir Cicek, Aysenur Pac Kisaarslan, Muammer Hakan Poyrazoglu, Ruhan Düşünsel. Erciyes University, Pediatric Rheumatology, Kayseri, Turkey

Background: Intra-articular corticosteroid injection is a choice in the treatment of juvenile idiopathic arthritis (JIA), especially in large and few joints involvement. Intra-articular steroid injection provides relief in active synovitis but its effects on cartilage are controversial.

Objectives: The aim of this study is to evaluate the effect of intra-articular steroid injection on distal femoral cartilage thickness in patients with JIA by ultrasonography.

Methods: Distal femoral cartilage thicknesses were measured before the procedure and 6 months later by ultrasonography in the patients that were injected an intra-articular steroid to the knee.

Results: The mean age of the patients was $12.1 \pm 4,8$ years. Nine of patients were girls and 2 were boys. The mean disease duration was $5,1 \pm 4,2$ years. Ten patients had oligoarticular JIA and one patient had enthesitis-related arthritis. The number of patients injected to the right knee was 3 , the left knee was 5 and both the knee was 3 . The femoral cartilage thickness before the procedure was $3.0 \mathrm{~mm}$ [min-max 2.0-3.65 $\mathrm{mm}$ ], 6 months after the procedure was $2.95 \mathrm{~mm}$ [min-max 2.0-3.55 mm] and there was no statistical difference $(p>0,05)$.

Conclusion: In this study, no effect of intra-articular steroid treatment on cartilage was observed. However, the number of patients is lack. Therefore, we planned a comprehensive study with more patients.

\section{REFERENCES}

[1] Huppertz HI, Tschammler A, Horwitz AE, Schwab KO. Intraarticular corticosteroids for chronic arthritis in children: efficacy and effects on cartilage and growth, J Pediatr. 1995;127(2):317-21.

[2] Pradsgaard DØ, Hørlyck A, Spannow AH, Heuck C, Herlin T. A Comparison of Radiographic Joint Space Width Measurements Versus Ultrasonographic Assessment of Cartilage Thickness in Children with Juvenile Idiopathic Arthritis, JRheum 2019; 46:doi:10.3899/jrheum.170571.

Disclosure of Interests: None declared

DOI: 10.1136/annrheumdis-2019-eular.7973

\section{AB1043 CLINICAL OUTCOMES OF ANTI-NUCLEAR ANTIBODY POSITIVENESS IN THE 0-18 AGE GROUP: SINGLE- CENTER REAL-WORLD EXPERIENCE}

Nihal Sahin ${ }^{1}$, Aysenur Pac Kisaarslan ${ }^{1}$, Sumeyra Ozdemir Cicek ${ }^{1}$, Neslihan Günay ${ }^{2}$, Ayşe Seda Pinarbasi' ${ }^{2}$, Sibel Yel ${ }^{2}$, İsmail Dursun ${ }^{2}$, Muammer Hakan Poyrazoglu ${ }^{1}$, Hüseyin Kılıç ${ }^{3}$, Ruhan Düşünsel' ${ }^{1}{ }^{1}$ Erciyes University, Pediatric Rheumatology, Kayseri, Turkey; ${ }^{2}$ Erciyes University, Pediatric Nephrology, Kayseri, Turkey; ${ }^{3}$ Erciyes University, Medical Microbiology, Kayseri, Turkey

Background: Anti-nuclear antibody (ANA) assay is important in the diag nosis of autoimmune diseases. However, it has a poor positive predictive value and is detected positive in $10 \%$ of general population. In this study, the children that ANA assay was performed in a tertiary pediatric clinic, was evaluated and was aimed to investigate the clinical outcomes in positives.

Objectives: In this study, the children that ANA assay was performed in a tertiary pediatric clinic, was evaluated and was aimed to investigate the clinical outcomes in positives.

Methods: 0-18 age group patients that ANA assay was requested in the various clinics of Erciyes University were included. The patients with positive ANA assay and access to hospital records were retrospectively examined. Patients with and without autoimmune disease were identified as group 1 and group 2, respectively.

Results: The number of patients who required ANA assay in pediatric clinics was 3812. There was a positive ANA assay in 1010 of these patients. The medical records of 909 patients were reached. There were $345(38 \%)$ patients in group 1 and $564(62 \%)$ in group 2. In group 1 female gender was higher compared to group 2 ( $p<0.05)$. 